University of Nebraska - Lincoln

DigitalCommons@University of Nebraska - Lincoln

Roman L. Hruska U.S. Meat Animal Research

U.S. Department of Agriculture: Agricultural Center

Research Service, Lincoln, Nebraska

$10-1-2021$

\title{
Relationship of molecular breeding value for beef tenderness with heifer traits through weaning of their first calf
}

\author{
Robert A. Cushman \\ Gary L. Bennett \\ USDA ARS Roman L. Hruska U.S. Meat Animal Research Center \\ Richard G. Tait \\ USDA ARS Roman L. Hruska U.S. Meat Animal Research Center \\ Anthony K. McNeel \\ USDA ARS Roman L. Hruska U.S. Meat Animal Research Center \\ Eduardo Casas \\ USDA ARS Roman L. Hruska U.S. Meat Animal Research Center
}

Roman L. Hruska US Meat Animal Research Center, Bob.Cushman@ars.usda.gov

See next page for additional authors

Follow this and additional works at: https://digitalcommons.unl.edu/hruskareports

Part of the Beef Science Commons, and the Meat Science Commons

Cushman, Robert A.; Bennett, Gary L.; Tait, Richard G.; McNeel, Anthony K.; Casas, Eduardo; Smith, Timothy P.L.; and Freetly, Harvey C., "Relationship of molecular breeding value for beef tenderness with heifer traits through weaning of their first calf" (2021). Roman L. Hruska U.S. Meat Animal Research Center. 535.

https://digitalcommons.unl.edu/hruskareports/535

This Article is brought to you for free and open access by the U.S. Department of Agriculture: Agricultural Research Service, Lincoln, Nebraska at DigitalCommons@University of Nebraska - Lincoln. It has been accepted for inclusion in Roman L. Hruska U.S. Meat Animal Research Center by an authorized administrator of DigitalCommons@University of Nebraska - Lincoln. 
Authors

Robert A. Cushman, Gary L. Bennett, Richard G. Tait, Anthony K. McNeel, Eduardo Casas, Timothy P.L. Smith, and Harvey C. Freetly 


\title{
Relationship of molecular breeding value for beef tenderness with heifer traits through weaning of their first calf ${ }^{\text {th }}$
}

\author{
Robert A. Cushman*, Gary L. Bennett, Richard G. Tait Jr. ${ }^{1}$, Anthony K. McNeel ${ }^{2}$, \\ Eduardo Casas ${ }^{3}$, Timothy P.L. Smith, Harvey C. Freetly \\ USDA, Agricultural Research Service, U.S. Meat Animal Research Center, Clay Center, NE 68933-0166, United States
}

\section{A R T I C L E I N F O}

\section{Article history:}

Received 12 October 2020

Received in revised form

8 July 2021

Accepted 28 July 2021

Available online 31 July 2021

\section{Keywords:}

Heifer

Reproduction

Production

Genomic selection

\begin{abstract}
A B S T R A C T
Polymorphisms in $\mu$-calpain (CAPN1) that beneficially associate with beef tenderness are reported to antagonistically associate with calving day in beef heifers and post-partum interval to estrus in beef cows. We, therefore, hypothesized that a molecular breeding value for slice shear force, calculated based on CAPN1 and calpastatin (CAST) genotypes, would demonstrate an antagonistic relationship between genomically predicted slice shear force and ordinal calving date in replacement beef heifers. A secondary objective of this study was to evaluate the association of a polymorphism in diacylglycerol O-acyltransferase (DGAT1) with reproductive traits in beef heifers. One hundred eighty-seven MARC III heifers ( $1 / 4$ Angus, $1 / 4$ Hereford, $1 / 4$ Red Poll, and $1 / 4$ Pinzgauer) that had been selectively bred to increase the frequency of these polymorphisms were submitted for monthly ultrasound exams beginning at $333 \mathrm{~d}$ of age and continuing until the start of breeding to determine pubertal status. At the last exam before breeding, all antral follicles were counted, and the length and height of each ovary was measured to determine if genomic selection for slice shear force associated with ovarian follicle number. Calving date, calf gender, and calf birth weight were recorded at parturition. Regression analysis of the molecular breeding value for slice shear force of the heifers on ordinal calving date indicated no association between genomic prediction of tenderness and calving date $(P=0.16)$; however, there was a tendency for age at puberty to be delayed in heifers as genetic merit for tenderness improved $(P=0.09)$. The results of the present study indicate that within experimental precision, selecting for tenderness using genomic predictions had minimal or no antagonistic association with reproductive performance in heifers. Further analysis of reproductive performance as cows is needed within this population but applying these genetic markers to select for tenderness in steers does not antagonize reproductive traits influencing conception or first calf birth date and birth weight in replacement beef heifers.
\end{abstract}

Published by Elsevier Inc.

\footnotetext{
\& The U.S. Department of Agriculture (USDA) prohibits discrimination in all its programs and activities on the basis of race, color, national origin, age, disability, and where

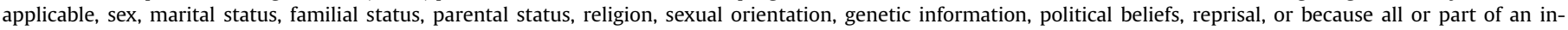

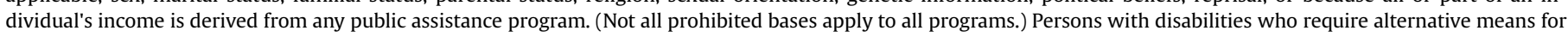

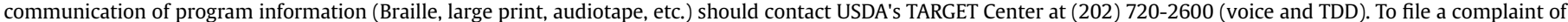

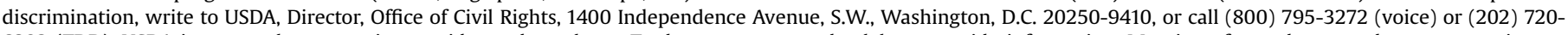

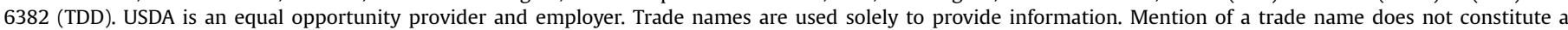

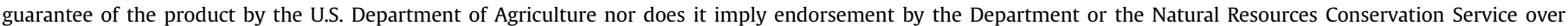
comparable products that are not named.

* Corresponding author.

E-mail address: bob.cushman@usda.gov (R.A. Cushman).

1 Present address: Neogen, GeneSeek Operations, 4131 N. 48th St., Lincoln, NE 68504, United States.

2 Present address: Zoetis, Inc., 333 Portage St., Kalamazoo, MI 49007, United States.

3 Present address: United States Department of Agriculture, Agricultural Research Service, National Animal Disease Center, Ames, IA 50010, United States.
} 


\section{Introduction}

Selection for meat tenderness in beef cattle may have off-target impacts on female reproduction. Genetic correlation estimates for carcass traits and female reproduction, based on measurements and pedigree, have been near zero [1]. Currently, genetic evaluations for many carcass traits depend increasingly on genetic markers in addition to carcass measurements. Because some of the genes used as markers for carcass traits also have been reported to have roles in uterine function and pregnancy [2], the relationships of marker-based genetic evaluations of carcass traits with reproductive traits may be different than those based solely on carcass measurements.

Polymorphisms in $\mu$-calpain (CAPN1) were associated with slice shear force in steers from cattle populations at the U.S. Meat Animal Research Center [3,4]. In other studies, alleles of CAPN1 that associated with tenderness also associated with increased post-partum interval to estrus in beef cows [5], indicating that using the marker to increase tenderness might delay re-breeding in the cow herd. Similarly, our laboratory reported a potential antagonistic relationship between two specific CAPN1 haplotypes associated with slice shear force in Angus steers and ordinal calving date of the first calf in their half-sisters [6]. We, therefore, believed the common CAPN1 haplotypes required further investigation to validate this potential antagonistic association between tenderness markers and calving day in beef heifers.

Polymorphisms in calpastatin (CAST) [3,7] were also associated with slice shear force in populations of steers at the U.S. Meat Animal Research Center. Additionally, polymorphisms in CAST were associated with fertility and reproductive longevity in Holstein cows [8,9]; however, a polymorphism in CAST was not associated with fertility traits in Angus heifers at the U.S. Meat Animal Research Center [6]. The current experiment was designed to test the hypothesis that a molecular breeding value for slice shear force, calculated based on CAPN1 and CAST genotypes, would demonstrate an antagonistic relationship directly between genomically predicted slice shear force and ordinal calving date in heifers. We further applied these data to survey the association of a polymorphism in diacylglycerol O-acyltransferase (DGAT1) on reproductive traits in beef heifers, because a polymorphism in this gene also has been reported to associate with days open in Holstein cows [9], and the selection process for the heifers in the present study increased the frequency of a DGAT1 minor allele.

\section{Materials and methods}

\subsection{Heifer population}

All animal procedures were approved by the U.S. Meat Animal Research Center (USMARC) Institutional Animal Care and Use Committee. A composite population of MARC III heifers ( $1 / 4$ Angus, $1 / 4$ Hereford, $1 / 4$ Red Poll, and $1 / 4$ Pinzgauer) was used in this experiment as described by Tait et al. [3]. Starting with mating in 2005, the population was selected to change frequencies of a haplotype in CAPN1 based on two single nucleotide polymorphisms (SNP), a SNP in its inhibitor CAST, and a SNP pair dinucleotide variant in DGAT1. The haplotype for CAPN1 is defined by the combinations of SNP 316 alleles C and G [rs17872000]; [10] and SNP 4751 alleles C and T [rs17872050]; [11] forming the common (higher frequency) haplotypes CAPN1hCC, CAPN1hGC, and CAPN1hGT. Haplotype CT occurs at very low frequency. The CAST minor allele C [CASTaC; rs109221039]; [12] was considerably less frequent than CASTaT. The dinucleotide substitution in DGAT1 [rs109234250 and rs109326954]; [13] results in a lysine AA allele (DGAT1aK) with lower frequency or an alanine AA allele (DGAT1aA). Samples of blood were collected in $10 \mathrm{~mL}$ syringes with $4 \%$ EDTA and frozen until DNA was extracted using a Qiagen QIAmp DNA mini blood kit (Qiagen, Valencia, CA). Genotypes were obtained using a MassArray system (Sequenom, Inc., San Diego, CA) as described by Stone et al. [14]. Selection goals were to equalize frequencies of the three common CAPN1 haplotypes at 0.33 and to increase minor allele frequencies for CAST and DGAT1 to improve statistical power of estimating genetic marker and breeding value associations [3].

An evaluation phase was conducted with calves born in 2010, 2011, and 2012. Steers and heifers were measured for pre-weaning traits while only steers were measured for growth in the feedlot, carcass, and meat traits. Estimates of marker effects for preweaning, steer growth, carcass, and meat traits were reported by Tait et al. [3]. Sires were chosen for heterozygosity for as many of the three genes as possible during the evaluation phase. These sires could potentially produce calves with any possible genotype combination except homozygotes of the CAPN1 haplotype not in the sire's heterozygous CAPN1 genotype. Statistical power was increased by comparing many genetic combinations within sire. About $63 \%$ of heifers born could be retained for evaluation and breeding each year. Retention was based on birth as a single, survival past weaning when blood was sampled for genotyping and successful genotyping of SNP. Heifers with over-represented genotypes were reduced by random culling within sire. Retained heifers $(n=187)$ were progeny of 24 sires and 151 dams. Table 1 shows the distribution of genotypes of retained heifers. Retained heifers were contemporary herd mates and half-sibs of the evaluation phase steers that were used to calculate the molecular breeding value for slice shear force described below (section 2.4).

\subsection{Heifer development}

After weaning, heifers were moved to the USMARC feedlot. Half were assigned to a standard heifer replacement diet and the other half to a stair-step development diet [15-17]. Heifers in the standard diet were fed for constant gain between weaning and breeding to attain approximately $65 \%$ of mature weight by breeding. Heifers assigned to the standard and stair-step diets were balanced across genotypes and sires. Data from this and three other populations were combined to evaluate diet effects [18].

Table 1

Frequencies of CAPN1, CAST, and DGAT1 genotypes of heifers $(n=187)$ evaluated for reproductive traits.

\begin{tabular}{lll}
\hline Genotypes & No. & $\%$ \\
\hline CAPN1 ${ }^{\text {a }}$ & & \\
CAPN1hCC:CAPN1hCC & 19 & 10.2 \\
CAPN1hCC:CAPN1hGC & 43 & 23.0 \\
CAPN1hCC:CAPN1hGT & 33 & 17.7 \\
CAPN1hGC:CAPN1hGC & 20 & 10.7 \\
CAPN1hGC:CAPN1hGT & 46 & 24.6 \\
CAPN1hGT:CAPN1hGT & 26 & 13.6 \\
CAST & & \\
CASTaC:CASTaC & 32 & 17.1 \\
CASTaC:CASTaT & 97 & 51.9 \\
CASTaT:CASTaT & 58 & 31.0 \\
DGAT1 & & \\
DGAT1aA:DGAT1aA & 70 & 37.4 \\
DGAT1aA:DGAT1aK & 87 & 46.5 \\
DGAT1aK:DGAT1aK & 30 & 16.0 \\
\hline
\end{tabular}

a Diplotypes composed of the 3 most common haplotypes of 2 ordered SNP in CAPN1 (316C or G; $4751 \mathrm{C}$ or T), e.g., CAPN1hCC:CAPN1hGT is the genotype formed by haplotypes CC and GT.

b Genotypes composed of the 2 SNP alleles in CAST (CASTaC and CASTaT).

c Genotypes composed of the Alanine (A) and Lysine (K) coding alleles in DGAT1. 


\subsection{Reproductive management of heifers}

Pubertal status of the heifers was determined by a series of three transrectal ultrasonographic examinations of the ovaries [6,19]. At an average of about 11-months of age, all heifers were weighed and submitted for ultrasonographic examination. The number and location of corpora lutea were recorded to determine pubertal status. Those that did not have a CL at 11-months of age were examined again at an average of about 12-months of age. Following weighing at 13-months of age, all heifers were submitted for ultrasonographic evaluation of the ovaries during which visible antral follicles were counted, the location of CL was recorded, and a crosssectional image of each ovary was measured for length and height $[19,20]$. Average palpation ages were 322,364 , and $405 \mathrm{~d}$ for heifers born in 2010; 331, 373, and $394 \mathrm{~d}$ for 2011; and 346, 372, and $403 \mathrm{~d}$ for 2012. The puberty status value analyzed was based on when puberty was first detected: 1,2 , or 3 for the first, second, or third palpation or 4 if puberty was not detected at any of the palpations.

Breeding of heifers began at an average age of $13.7 \mathrm{mo}$ and was 13-20 d after the last ultrasonographic reproductive tract evaluation. Heifers born in 2010 were bred to 15 bulls by AI for $21 \mathrm{~d}$ and then divided in two breeding pastures with a single bull in each pasture for $42 \mathrm{~d}$. Personnel assigning heifers to AI bulls and pastures did not have access to genotypes. Heifers born in 2011 and 2012 were bred by natural service for $63 \mathrm{~d}$ in a single pasture with four bulls and three bulls, respectively. Approximately $50 \mathrm{~d}$ after removal of the bulls, heifers were evaluated for pregnancy by transrectal ultrasonography. Hip height, body weight and body condition score (9point scale; 1 = emaciated, $9=$ obese) were collected at pregnancy evaluation (18 months, Table 2) and before first calving season (23 months, Table 2). Calving date, calf sex, and calf birth weight were recorded in the USMARC database at the time of tagging. At weaning, the weaning weight of the calf was added to the USMARC database.

\subsection{Molecular breeding value calculation and regression analysis}

A regression analysis was performed to estimate the effects of selection to reduce slice shear force (SSF) or increase number of DGAT1 K alleles on heifer traits. A molecular breeding value for SSF (MBVSSF) was calculated using SSF estimates for CAST and CAPN1 from steer herd mates [3] and each heifer's genotypes for CAST and CAPN1. Values for MBVSSF averaged $2.81 \mathrm{~kg}(0.0-4.11 \mathrm{~kg})$ with lower values associated with tender meat (Fig. 1) and number of $\mathrm{K}$ alleles for DGAT1 $(0,1$, or 2$)$.

Key dependent variables are presented in Table 2. Dependent variables for the heifers were pubertal status, antral follicle count, ovarian length (the average of the two ovaries within a heifer), ovarian height (the average of the two ovaries within a heifer), body weights at key management points, and hip heights at those same management times. Dependent variables for the first calf included calving date, calf birth weight, and calf weaning weight. Statistical models were fitted using the GLIMMIX procedure in SAS (Cary, NC). The basic statistical model for traits included fixed effects of three birth years, four ages of dams of the heifers $(2,3,4$, or 5 years and older), two heifer development diets, and a regression coefficient for age at measurement when appropriate. Age of dam of the heifer was included in the model because in previous studies age of the dam has influenced reproductive performance of heifers [21,22]. Sire of the heifer was included as a random effect. Fixed regression coefficients for MBVSSF and DGAT1aK were both added to the model. Analyses for continuous traits were considered normally distributed. Percentage traits were considered to have a binary distribution and analyzed with logit link. The four categories of puberty determination were considered an ordered multinomial distribution and analyzed with a cumulative probit link.
Table 2

Means, unadjusted SD, and ranges for traits and ages.

\begin{tabular}{|c|c|c|c|c|c|}
\hline Item & No. & Mean & SD & Min & Max \\
\hline Birth date, ordinal & 187 & 104.0 & 19.0 & 66.0 & 157.0 \\
\hline 12-mo ave. BW ${ }^{\mathrm{a}}, \mathrm{kg}$ & 187 & 325.0 & 42.0 & 211.0 & 417.0 \\
\hline 18-mo BW, kg & 187 & 389.0 & 35.0 & 294.0 & 501.0 \\
\hline 18-mo height, cm & 187 & 123.2 & 3.5 & 112.0 & 132.0 \\
\hline 18-mo condition score & 187 & 5.5 & 0.6 & 4.0 & 7.0 \\
\hline 23-mo BW, kg & 166 & 430.0 & 40.0 & 305.0 & 528.0 \\
\hline 23-mo height, cm & 166 & 126.8 & 3.9 & 116.0 & 137.0 \\
\hline 23-mo condition score & 166 & 5.5 & 0.6 & 4.0 & 7.0 \\
\hline Age 1st palpation ${ }^{\mathrm{b}}, \mathrm{d}$ & 187 & 333.0 & 21.0 & 273.0 & 371.0 \\
\hline Total follicles, no. & 187 & 21.7 & 8.4 & 7.0 & 46.0 \\
\hline Ovarian length, $\mathrm{mm}^{\mathrm{c}}$ & 187 & 26.8 & 4.0 & 13.0 & 36.0 \\
\hline Ovarian height, $\mathrm{mm}^{\mathrm{c}}$ & 187 & 13.9 & 2.2 & 5.0 & 19.0 \\
\hline Calf birth date, ordinal & 162 & 89.0 & 16.0 & 59.0 & 134.0 \\
\hline Calf birth BW, kg & 162 & 33.4 & 4.4 & 17.0 & 46.0 \\
\hline Calf weaning age, $d$ & 152 & 174.0 & 17.0 & 127.0 & 207.0 \\
\hline Calf weaning BW, kg & 152 & 183.0 & 26.0 & 121.0 & 248.0 \\
\hline
\end{tabular}

${ }^{a}$ Average of $4 \mathrm{wt}$ (average ages of 337, 359, 380, and $400 \mathrm{~d}$ ) spanning the 3 palpation dates for puberty.

b Heifers were palpated to determine puberty on 3 dates each year. All were palpated on the 1 st and 3rd dates. Those not pubertal on the first date were also palpated on the 2 nd date.

Average length and average height of the two ovaries within a heifer.

\section{Results}

Descriptive statistics for the traits evaluated are presented in Table 2. Contrary to the hypothesis, regression of the MBVSSF on heifer performance traits did not identify a relationship between genetic merit for tenderness and heifer ordinal calving date (Table 3). There was a tendency for age at puberty to be delayed as genetic merit for tenderness improved ( $P=0.09$; Table 3 and Fig. 2). There was no association of MBVSSF with antral follicle count or average size of the ovaries (Table 3).

As number of $\mathrm{K}$ alleles for DGAT1 increased, first calf birth weight increased ( $P=0.04$; Table 3 ) and calving day tended $(\mathrm{P}=0.08)$ to increase. There was no association of number of DGAT1 $\mathrm{K}$ alleles with antral follicle count (Table 3); however, there was a small but significant genetic association of the number of $\mathrm{K}$ alleles for DGAT1 with height of the ovary $(\mathrm{P}=0.01)$ measured on the ultrasound screen, such that height of the ovary increased as the number of $\mathrm{K}$ alleles increased. Hip height at 23 months of age also increased as the number of $\mathrm{K}$ alleles for DGAT1 increased $(\mathrm{P}=0.04)$.

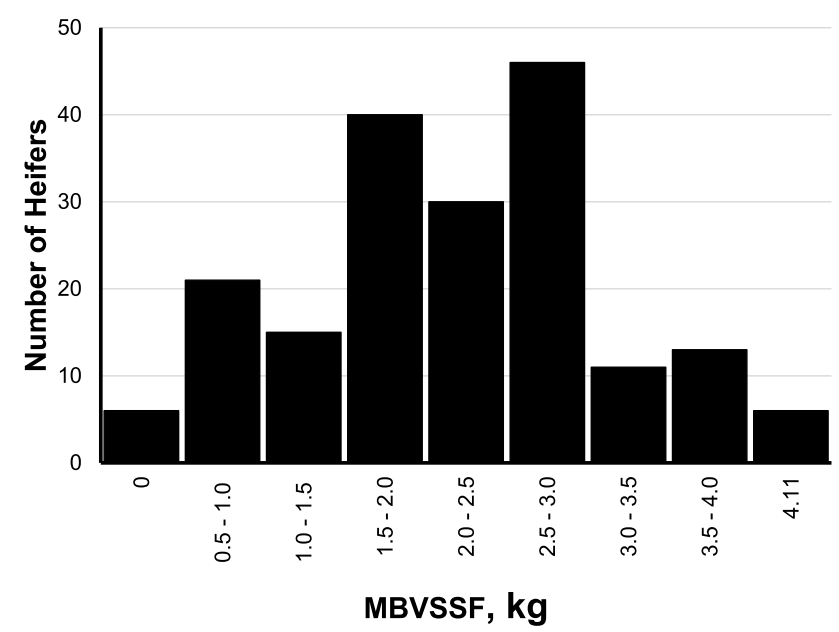

Fig. 1. Distribution of heifers within MBVSSF based on CAPN1 and CAST genotypes. 


\section{Discussion}

The novel aspect of the current study is using molecular breeding value for slice shear force instead of component genotypes to test the hypothesis that genomic selection for beef tenderness would increase ordinal calving date in beef heifers. Combining CAPN1 and CAST into a single breeding value is a more holistic approach to evaluating antagonisms with application of genomic selection for beef tenderness. Because these were replacement heifers not destined for the abattoir, this provided a method to further validate the potential antagonism observed in our previous study for two haplotypes of CAPN1 (Tait) in a different population of heifers. Based on our previous study, we believed that ordinal calving date in heifers might be delayed as genetic merit for tenderness improved [6]; however, the results of the current study did not support this hypothesis. Because previous studies have demonstrated a beneficial relationship between the number of antral follicles detectable by ultrasonography at a pre-breeding exam and calving day in heifers [19,23], we investigated the relationship between MBVSSF and antral follicle count. There was no change in antral follicle count across the range of the MBVSSF. Differences in the association of CAPN1 on ordinal calving date between this study in MARC III composites and our previous study in Angus [6] could be due to population differences or the use of combined breeding value vs. CAPN1 haplotypes and CAST genotypes.

Age at puberty tended to be delayed in heifers that were predicted to have greater tenderness using the MBVSSF. While only a tendency, this is supportive of the previously observed delay in calving day in USMARC Angus heifers having the CAPN1 allele that associated with tenderness [6] and the increased post-partum interval in cows having the CAPN1 allele that associated with

Table 3

Estimated regression coefficients for molecular breeding value for slice shear force (MBVSSF) and number of K alleles for DGAT1.

\begin{tabular}{|c|c|c|c|c|c|c|}
\hline \multirow[t]{2}{*}{ Trait } & \multicolumn{3}{|l|}{ MBVSSF } & \multicolumn{3}{|c|}{ No. of K Alleles of DGAT1 } \\
\hline & Estimate & SE & $\mathrm{P}$ & Estimate & SE & P-value \\
\hline 12-mo ave. weight ${ }^{\mathrm{a}}, \mathrm{kg}$ & 1.0 & 2.0 & 0.63 & 3.6 & 2.7 & 0.18 \\
\hline 18-mo weight, kg & 1.9 & 2.3 & 0.42 & 3.9 & 3.1 & 0.22 \\
\hline 18-mo height, $\mathrm{cm}$ & -0.03 & 0.25 & 0.63 & 0.5 & 0.3 & 0.16 \\
\hline 18-mo condition score & 0.02 & 0.04 & 0.63 & 0.1 & 0.1 & 0.37 \\
\hline 23-mo weight, kg & 3.8 & 2.6 & 0.15 & 4.4 & 3.4 & 0.19 \\
\hline 23-mo height, $\mathrm{cm}$ & 0.1 & 0.3 & 0.65 & 0.8 & 0.4 & 0.04 \\
\hline 23-mo condition score & 0.0 & 0.1 & 0.87 & -0.0 & 0.1 & 0.92 \\
\hline Puberty age, d & -3.7 & 2.2 & 0.09 & -3.5 & 2.9 & 0.23 \\
\hline Puberty detection value $^{\mathrm{b}}$ & -0.1 & 0.1 & 0.13 & -0.1 & 0.1 & 0.21 \\
\hline Total follicles & 0.7 & 0.7 & 0.25 & 1.3 & 0.9 & 0.13 \\
\hline Ovarian length ${ }^{c}, \mathrm{~mm}$ & 0.5 & 0.3 & 0.07 & 0.4 & 0.4 & 0.28 \\
\hline Ovarian height $^{\mathrm{c}}, \mathrm{mm}$ & -0.0 & 0.2 & 0.88 & 0.5 & 0.2 & 0.01 \\
\hline Calving day ${ }^{\mathrm{d}}$, ordinal & -1.9 & 1.3 & 0.16 & 3.1 & 1.8 & 0.08 \\
\hline Calf birth weight ${ }^{\mathrm{d}}, \mathrm{kg}$ & -0.3 & 0.4 & 0.34 & 1.0 & 0.5 & 0.04 \\
\hline Calf weaning weight ${ }^{\mathrm{d}}, \mathrm{kg}$ & -0.2 & 1.6 & 0.90 & 0.1 & 1.9 & 0.94 \\
\hline Pregnant at $18-\mathrm{mo}^{\mathrm{e}}, \%$ & 3.2 & 2.4 & 0.20 & 2.4 & 3.3 & 0.47 \\
\hline Pregnant at calvinge,$\%$ & 4.3 & 2.6 & 0.11 & 3.0 & 3.6 & 0.39 \\
\hline Weaned a calfe, \% & 4.8 & 3.0 & 0.12 & 4.0 & 4.1 & 0.33 \\
\hline
\end{tabular}

${ }^{a}$ Average of 4 wt (average ages of 337, 359, 380, and $400 \mathrm{~d}$ ) spanning the 3 palpation dates for puberty.

b Values were based on which of 3 palpation dates puberty was first detected. Estimates and SE are from analysis using an identity link and P-values are from analysis using cumulative probit link. Negative values indicate numerically earlier puberty detection associated with increased MBVSSF and number of $\mathrm{K}$ alleles for DGAT1.

c Average length and average height of the two ovaries within a heifer.

d Regression calf's birth date, birth weight, and weaning weight on heifer dam's MBVSSF and number of $\mathrm{K}$ alleles for DGAT1.

e Percentage of heifers at breeding. Estimates and SE are from analysis using an identity link and $\mathrm{P}$ values are from analysis using a logit link.

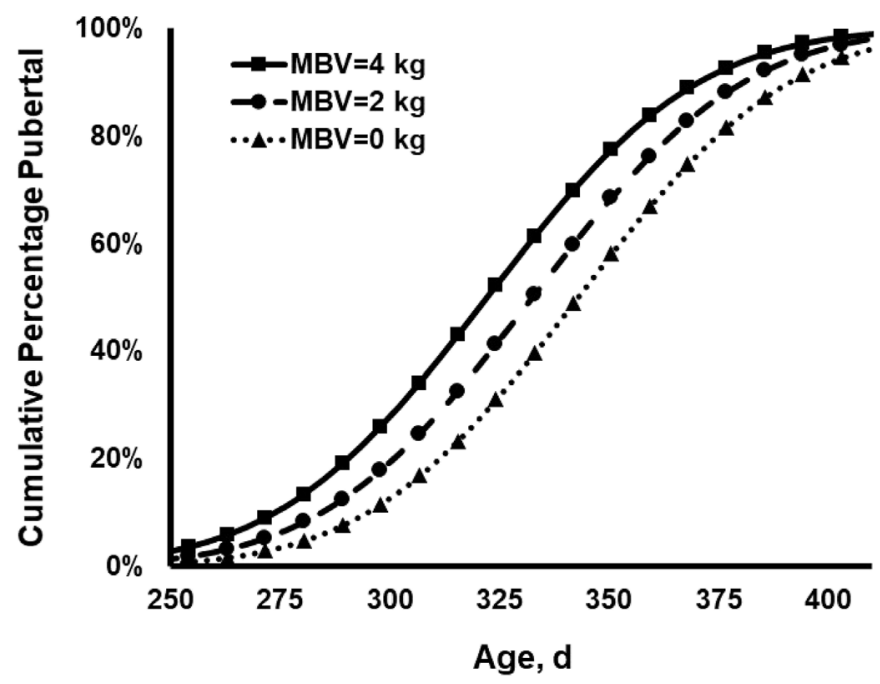

Fig. 2. Predicted percentage of pubertal heifers between 250 and $400 \mathrm{~d}$ of age based on molecular breeding value for slice shear force. There was a tendency $(P=0.09)$ for puberty to be delayed as genetic merit for slice shear force improved.

tenderness [5]. Breed differences across the three studies may explain differences in intensity and form of the phenotype observed. It is, however, unlikely that the degree of these antagonisms is enough to seriously impede reproductive efficiency in the heifer or the cow.

A recent study reported no association of the DGAT1 polymorphism with reproductive traits in Japanese Black (Wagyu) cows [24]. Overall, the results of the present study would agree with that conclusion, although there was a tendency for calving day to be delayed by an increase in the number of $\mathrm{K}$ alleles for DGAT1. An interesting result of the present study was an association of number of DGAT1 K alleles with height of the ovary measured on the ultrasound screen at the pre-breeding exam. To our knowledge, there are no published roles of DGAT1 in ovarian development or function. This could be a false positive because a difference of $0.5 \mathrm{~mm}$ is almost definitely beyond the sensitivity of the calipers. Furthermore, there is no reason to think that a difference in ovarian height, if real, influences reproductive performance in beef heifers in any way. Additional verification and investigation of the biological implications of this association are warranted before any conclusions can be drawn from these results.

The identification of the association of the number of $\mathrm{K}$ alleles for DGAT1 with hip height at 23 months of age is also novel to the current study and will require further validation. While DGAT1 is well-known for its role in triglyceride synthesis, it also has been demonstrated to have a role in bone development and bone health [25]. Thus, the increasing hip height as cows approach maturity suggests the possibility that DGAT1 may affect closure of the bone growth plates, although it is intriguing that this difference in long bone growth was not observed earlier in life. This may be because at a younger age, the influence of DGAT1 on bone development is reduced compared to genes with a greater role in bone development. Bone health is important for structural soundness and longevity. Selection for this marker could, therefore, help improve longevity in the cow herd and decrease replacement costs.

Finally, there was an association between maternal DGAT1 genotype and first calf birth weight. Given the role of DGAT1 in metabolic processes, the most likely mechanism would be a change in nutrient partitioning that allows for greater nutrient supply to the developing fetus, but this, also, is a previously unrecognized effect of DGAT1 that will require further investigation before we can 
be sure that we can use this marker to select for calf birth weight in beef cows.

\section{Conclusion}

The results of the present study indicate that within experimental precision, selecting for more tender MBVSSF had minimal or no antagonistic influence on reproductive performance in heifers. Cow-calf producers should be able to use these genetic markers to improve tenderness within their herd without negatively impacting reproductive function of replacement heifers.

\section{Author credit statement}

Experimental Design: Cushman, Bennett, Smith, Casas, Heifer Management and Ultrasound Data Collection: Cushman, McNeel, Freetly, Genotyping and genetic selection: Bennett, Smith, Casas, Data analysis: Bennett, Tait, Manuscript preparation: Cushman, Bennett, Tait, McNeel, Smith, Casas, Freetly.

\section{Declaration of competing interest}

The authors have no conflicts of interest to report.

\section{Acknowledgment}

The authors thank USMARC Cattle Operations for care and management of the heifers and assistance in collecting data, and Donna Griess for assistance with manuscript preparation.

\section{References}

[1] Splan RK, Cundiff LV, Van Vleck LD. Genetic parameters for sex-specific traits in beef cattle. J Anim Sci 1998;76:2272-8.

[2] Kumagai K, Ozaki Y, Nakanishi T, Inomata M, Furuno T, Nakanishi M, et al. Role of mu-calpain in human decidua for recurrent miscarriage. Am J Reprod Immunol 2008;59:339-46.

[3] Tait Jr RG, Shackelford SD, Wheeler TL, King DA, Keele JW, Casas E, et al. CAPN1, CAST, and DGAT1 genetic effects on preweaning performance, carcass quality traits, and residual variance of tenderness in a beef cattle population selected for haplotype and allele equalization. J Anim Sci 2014;92:5382-93.

[4] Bennett GL, Tait Jr RG, Shackelford SD, Wheeler TL, King DA, Casas E, et al Enhanced estimates of carcass and meat quality effects for polymorphisms in myostatin and $\mu$-calpain genes. J Anim Sci 2019;97:569-77.

[5] Collis E, Fortes MR, Zhang Y, Tier B, Schutt K, Barendse W, et al. Genetic variants affecting meat and milk production traits appear to have effects on reproduction traits in cattle. Anim Genet 2012;43:442-6.

[6] Tait Jr RG, Cushman RA, McNeel AK, Casas E, Smith TPL, Freetly HC, et al. muCalpain (CAPN1), calpastatin (CAST), and growth hormone receptor (GHR) genetic effects on Angus beef heifer performance traits and reproduction. Theriogenology 2018;113:1-7.

[7] Tait Jr RG, Shackelford SD, Wheeler TL, King DA, Casas E, Thallman RM, et al. mu-Calpain, calpastatin, and growth hormone receptor genetic effects on preweaning performance, carcass quality traits, and residual variance of tenderness in Angus cattle selected to increase minor haplotype and allele frequencies. J Anim Sci 2014;92:456-66.

[8] Garcia MD, Michal JJ, Gaskins CT, Reeves JJ, Ott TL, Liu Y, et al. Significant association of the calpastatin gene with fertility and longevity in dairy cattle. Anim Genet 2006;37:304-5.

[9] Hill R, Canal A, Bondioli K, Morell R, Garcia MD. Molecular markers located on the DGAT1, CAST, and LEPR genes and their associations with milk production and fertility traits in Holstein cattle. Genet Mol Res 2016;15.

[10] Page BT, Casas E, Heaton MP, Cullen NG, Hyndman DL, Morris CA, et al. Evaluation of single-nucleotide polymorphisms in CAPN1 for association with meat tenderness in cattle. J Anim Sci 2002;80:3077-85.

[11] White SN, Casas E, Wheeler TL, Shackelford SD, Koohmaraie M, Riley DG, et al. A new single nucleotide polymorphism in CAPN1 extends the current tenderness marker test to include cattle of Bos indicus, Bos taurus, and crossbred descent. J Anim Sci 2005:83:2001-8.

[12] Casas E, White SN, Wheeler TL, Shackelford SD, Koohmaraie M, Riley DG, et al. Effects of calpastatin and micro-calpain markers in beef cattle on tenderness traits. J Anim Sci 2006;84:520-5.

[13] Grisart B, Coppieters W, Farnir F, Karim L, Ford C, Berzi P, et al. Positional candidate cloning of a QTL in dairy cattle: identification of a missense mutation in the bovine DGAT1 gene with major effect on milk yield and composition. Genome Res 2002;12:222-31.

[14] Stone RT, Grosse WM, Casas E, Smith TP, Keele JW, Bennett GL. Use of bovine EST data and human genomic sequences to map 100 gene-specific bovine markers. Mamm Genome 2002;13:211-5.

[15] Freetly HC, Vonnahme KA, McNeel AK, Camacho LE, Amundson OL, Forbes ED, et al. The consequence of level of nutrition on heifer ovarian and mammary development. J Anim Sci 2014;92:5437-43.

[16] Amundson OL, Fountain TH, Larimore EL, Richardson BN, McNeel AK, Wright EC, et al. Postweaning nutritional programming of ovarian development in beef heifers. J Anim Sci 2015;93:5232-9.

[17] Abedal-Majed MA, Kurz SG, Springman SA, McNeel AK, Freetly HC, Largen V, et al. Vascular endothelial growth factor A isoforms modulate follicle development in peripubertal heifers independent of diet through diverse signal transduction pathways. Biol Reprod 2020;102:680-92.

[18] Freetly HC, Cushman RA, Bennett GL. Production performance of cows raised with different post-weaning growth patterns. Trans Anim Sci 2021;5:1-7. https://doi.org/10.1093/tas/txab031. txab031.

[19] McNeel AK, Cushman RA. Influence of puberty and antral follicle count on calving day in crossbred beef heifers. Theriogenology 2015;84:1061-6.

[20] Cushman RA, Allan MF, Kuehn LA, Snelling WM, Cupp AS, Freetly HC. Evaluation of antral follicle count and ovarian morphology in crossbred beef cows: investigation of influence of stage of the estrous cycle, age, and birth weight. J Anim Sci 2009;87:1971-80.

[21] Akbarinejad V, Gharagozlou F, Vojgani M, Bagheri Amirabadi MM. Nulliparous and primiparous cows produce less fertile female offspring with lesser concentration of anti-Müllerian hormone $(\mathrm{AMH})$ as compared with multiparous cows. Anim Reprod Sci 2018;197:222-30.

[22] Tenley SC, Gomes RS, Rosasco SL, Northrop EJ, Rich JJJ, McNeel AK, et al. Maternal age influences the number of primordial follicles in the ovaries of yearling Angus heifers. Anim Reprod Sci 2019;200:105-12.

[23] Cushman RA, McNeel AK, Freetly HC. The impact of cow nutrient status during the second and third trimesters on age at puberty, antral follicle count, and fertility of daughters. Livest Sci 2014;162:252-8.

[24] Kawaguchi F, Tsuchimura M, Oyama K, Matsuhashi T, Maruyama S, Mannen H, et al. Effect of DNA markers on the fertility traits of Japanese Black cattle for improving beef quantity and quality. Arch Anim Breed 2020;63:9-17.

[25] Drosatos-Tampakaki Z, Drosatos K, Siegelin Y, Gong S, Khan S, Van Dyke T, et al. Palmitic acid and DGAT1 deficiency enhance osteoclastogenesis, while oleic acid-induced triglyceride formation prevents it. J Bone Miner Res 2014;29:1183-95. 